\title{
Medication Adherence and the Role of Pictograms in Medication Counselling of Chronic Patients: a Review
}

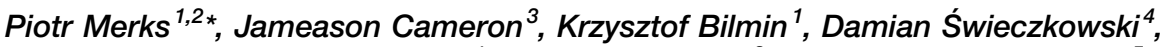 \\ Tomira Chmielewska-lgnatowicz ${ }^{1}$, Tomasz Harężlak ${ }^{2}$, Katarzyna Białoszewska ${ }^{5}$, \\ Katarina Fehir Sola ${ }^{6}$, Miłosz $J$ Jaguszewski ${ }^{4}$ and Regis Vaillancourt ${ }^{3}$ \\ ${ }^{1}$ Faculty of Medicine, Collegium Medicum, Cardinal Stefan Wyszyński University, Warsaw, Poland, ${ }^{2}$ Department of \\ Pharmaceutical Technology, Collegium Medicum, Nicolaus Copernicus University, Toruń, Poland, ${ }^{3}$ Department of Pharmacy, \\ Children's Hospital of Eastern Ontario, Centre Hospitalier pour Enfants de L'est de L'Ontario, Ottawa, ON, Canada, ${ }^{4}$ First \\ Department of Cardiology, Medical University of Gdansk, Gdańsk, Poland, ${ }^{5}$ Department of Paediatric Dentistry, Medical \\ University of Warsaw, Warsaw, Poland, ${ }^{6}$ Pharmacy of Bjelovar, Bjelovar, Croatia
}

\section{OPEN ACCESS}

Edited by:

Johanna Catharina Meyer, Sefako Makgatho Health Sciences

University, South Africa

Reviewed by: Brian Godman,

University of Strathclyde,

United Kingdom

Joseph O Fadare,

Ekiti State University, Nigeria

*Correspondence:

Piotr Merks

p.merks@uksw.edu.pl

Specialty section: This article was submitted to Drugs Outcomes Research and

Policies,

a section of the journal

Frontiers in Pharmacology

Received: 10 July 2020

Accepted: 19 July 2021

Published: 19 August 2021

Citation:

Merks P, Cameron J, Bilmin K Świeczkowski $D$,

Chmielewska-lgnatowicz $T$ Harężlak T, Białoszewska K, Sola KF, Jaguszewski MJ and Vaillancourt $R$ (2021) Medication Adherence and the Role of Pictograms in Medication Counselling of Chronic Patients:

a Review.

Front. Pharmacol. 12:582200. doi: 10.3389/fphar.2021.582200
Pharmaceutical care requires a patient-centered approach, focusing on the ability of patients to understand drug-related information and follow the instructions delivered by pharmacists as well as other health-care providers included in the circle of care. With the goal of ensuring the prescribed use of medications, called medication adherence, healthcare providers have to consider many risk factors such as geography (culture), social economic status, age, and low literacy that may predispose patients to non-adherence, and considerations have to be made for chronic patients living with life-long disease states. The aim of this review is to provide a balanced and comprehensive review outlining a number of different medication counselling and education approaches that have been used to try to improve medication adherence and health outcomes with the use of clear and concise graphic illustrations-called pictograms. By highlighting the current landscape of the general use and efficacy of pharmaceutical pictograms to aid in the knowledge and recall of drug-related information, as well as outlining specific medication adherence outcomes with pharmaceutical pictograms in chronic patients, the current review describes the need for health-care providers to move beyond the traditional didactic methods of oral and verbal communication with patients regarding medication-taking behavior.

Keywords: pictograms, medication adherence, pharmaceutical care, medication counselling, health literacy

\section{INTRODUCTION}

Pharmaceutical care requires a patient-centered approach, focusing on the ability of patients to understand drug-related information and follow instructions delivered by pharmacists as well as other health-care providers included in the circle of care. Pharmaceutical care was defined by Hepler and Strand as the responsible provision of drug therapy for the purpose of achieving specific drugrelated outcomes (i.e., cure a disease, eliminate or reduce symptomatology, arrest or slow disease progression, or prevent disease onset) as well as improve overall wellbeing and quality of life of the patient (Hepler and Strand, 1990). Pharmaceutical care involves a multidirectional communication process whereby the pharmacist cooperates with the patient, physician, and other healthcare professionals in designing, implementing, and monitoring a therapeutic plan that will result in 
specific therapeutic outcomes with the goal of providing direct benefits for the patient. At the center of this balancing of treatment and outcomes is the patient, where medication adherence is the fulcrum that ultimately dictates success and literacy is the tool that tips the balance towards successful health outcomes.

\section{The Role of Literacy in Health: A Focus on Chronic Patients}

Poor literacy and health literacy are serious problems with worldwide health burden and are major contributors to negative patient outcomes. In the United States, it is estimated that $47.0 \%$ of adults have difficulty understanding health-related information and lack the necessary skills to manage their health adequately (Institute of Medicine US Committee on Health Literacy, 2004); in Canada, it is an estimated $60.0 \%$ people (Canadian Council on Learning, 2008); and a recent survey of European countries suggests that $47.6 \%$ of all adults have limited health literacy skills with major differences among countries, ranging from $28.7 \%$ in the Netherlands to $62.1 \%$ in Bulgaria (Sørensen et al., 2015). For Africa, data on health literacy is scarce but it has been noted that the average literacy rate was $63 \%$ in 2015, where approximately one third of the population could not read and write (UNESCO Institute for Statistics, 2013). Clearly there is a global health literacy crisis that affects both developing and developed nations. It is also clear that improving the patient's ability to understand and make appropriate decisions about medication-taking behavior depends on improving both literacy and health literacy by ensuring the information is both accessible and understood.

Low health literacy has also been associated with poor medication and treatment adherence in healthy and in chronic patients (Kalichman et al., 2000; Youmans and Schillinger, 2003; Ngoh, 2009).

Patients with chronic diseases and poor health literacy are generally at risk for poor health outcomes and low quality of life, and they generate a greater burden for healthcare systems. Specifically, poor health literacy is associated with higher allcause mortality rates among patients with heart failure (Peterson et al., 2011). Furthermore, in the setting of chronic diseases such as hypertension, poor adherence limits the effectiveness of therapies proven to improve cardiovascular outcomes (Roccella, 1997) and can result in hospitalization and higher health care costs (Sokol et al., 2005). In patients living with diabetes, low health literacy has been associated with poor glycaemic control and therefore exposure to diabetes complications (retinopathy) (Bailey et al., 2014). In patients living with chronic-obstructive pulmonary disease a positive association exists with disease severity and utility of emergency healthcare services, whereas a negative association emerges with disease severity and quality of life specific to respiratory disorders, as well as helplessness in the face of illness (Omachi et al., 2013). It should be noted that some of the data on lower health literacy and nonadherence are clear (e.g. medication dosing), however the relationship between literacy and adherence is not equivocal as there are studies that have failed to find any relationships (Davis et al., 2006; Pignone and DeWalt, 2006).

\section{Chronic Patients, Health Literacy, and Medication Adherence}

In 2005, 35 million people were estimated to have died from chronic diseases worldwide, representing more than $60 \%$ of all deaths globally (World Health Organization, 2005). Nearly half of all adults and approximately $8 \%$ of children (aged 5-17 years) worldwide have a chronic disease, where chronic diseases are defined broadly as conditions that last 1 year or more and require ongoing medical attention or limit activities of daily living or both (Centres for Disease Control and Prevention). Furthermore, four in ten adults have two or more chronic diseases, leaving millions requiring multiple lifelong medications for control (Buttorff et al., 2017). Poor medication adherence is a key hindrance in combating the challenges of public health related to the management of chronic conditions in both developed and developing countries (Ingersoll and Cohen, 2008). The World Health Organization defines adherence as "the extent to which a person's behavior - taking medication, following a diet, and/or executing lifestyle changes, corresponds with agreed recommendations from a health care provider" (World Health Organization, 2003). Medication adherence is defined as the degree to which a patient adheres to the prescribed dose and interval of their medication regimen and it includes the initiation of the treatment, the implementation of the prescribed regime, and the discontinuation of the pharmacotherapy (Vrijens et al., 2012). Nonadherence to medication ranges between 25 and 50\%, with higher numbers of nonadherence found in patients living in less developed countries and in patients living with chronic disease (DiMatteo, 2004). The impact of nonadherence on the patient's health can be severe due to the reduced benefit of their medication, resulting in further disease progression or delayed recovery. This can lead to an increased risk of hospitalization and possibly death. Notably, the risk of hospitalization can be increased by over $100 \%$ in patients suffering from certain chronic conditions such as hypertension, diabetes, congestive heart failure and hypercholesterolaemia (Sullivan et al., 1990).

Indeed, in reports of medication adherence in chronically ill patients, it has consistently been reported that approximately $50 \%$ of these patients do not take their medications as prescribed (Dunbar-Jacob and Mortimer-Stephens, 2001) and in certain diseases such as hypertension, where the patient may present as asymptomatic, the incidence of non-adherence may approach $80 \%$ (Brown et al., 2016). Such findings are not shocking when considering the complexity of taking multiple medications, where patients are required to read their medication labels and associated medical information, comprehend instructions, perform numeric tasks (e.g., calculating the number of tablets to take in a day and in a single dose), and must decide what actions are required in the case of a missed dose or to monitor themselves for side effects (Youmans and Schillinger, 2003). Taken together, in order to ensure overall adherence and patient safety, a proactive approach of the health care provider is integral in identifying and preventing potential drug-related 
problems and resolving actual ones (Hepler and Strand, 1990), as well as communicating this complex information in the context of each patient's own health literacy level.

\section{Review Aims: Medication Adherence in Chronic Patients and the Role of Pictograms}

The problem of low health literacy should be considered in the broad spectrum of the current challenges of healthcare systems. Both physicians and pharmacists tend to have less time to spend on education for the patient (Gazmararian et al., 2003) so the modern healthcare systems must focus on the inter-relationship between self-management or self-efficacy from the patient, and an open dialogue with the health care team. People with lowliteracy indicate that they experience a high cognitive load when required to read written drug information, which is reflected in their comments about the time and effort it takes to read and process the information (Mayer, 2002); indeed, similar findings exist in older patients living with chronic conditions (Park et al., 1994). Taken together, the aim of this review is to provide a balanced and comprehensive review outlining a number of different medication counselling and education approaches that have been used to try to improve medication adherence and health outcomes, with a specific focus on the use of clear and concise graphic illustrations-called pictograms, to help improve patient outcomes. By highlighting the current landscape of the general use and efficacy of pharmaceutical pictograms to aid in the knowledge and recall of drug-related information, as well as outlining specific medication adherence outcomes with pharmaceutical pictograms in chronic patients, the objective of this review is to describe the need for health-care providers from low- and middle-income countries to high-income countries to move beyond the traditional didactic methods of oral and verbal communication with patients in order to improve medicationtaking behavior.

\section{METHODOLOGY}

The methodology was as follows: the search was conducted with the use of Medline, EmBase, Cochrane Library and Google Scholar. We used key words like: pictogram, graphic, picture, pictorial aid, label. The search was conducted from January to March 2020. No limitation regarding the date of publication was set. No documentation regarding the collection of publications was made.

In the first step of the review, the titles of the articles were carefully checked. If the title obviously indicated that the article was not suitable for the scope of our review, the reference was rejected. If the title suggested the presence of data consistent with our interests, the publication was further analyzed. In the next step, abstract was assessed, and if still applicable, full text was analyzed. We wanted to include original studies assessing the utility, efficacy and patient feedback regarding pictograms in the context of chronic diseases among teenagers and adults, and so the criteria were defined. In our review, we aimed to present the broad spectrum of the concepts of pharmaceutical care and how pictograms can be implemented into this philosophy.

\section{MEDICATION ADHERENCE: THE CURRENT LANDSCAPE}

The topic of medication adherence has been widely studied as evidenced by the fact that there are over 200 systematic reviews on the topic. According to the WHO, there are several reasons that have been identified for non-adherence, including: low health literacy, cost to patients, fear of adverse drug effects, lack of social support, etc.). Regarding the study design of the interventions that have assessed adherence, a Cochrane systematic review by Nieuwlaat et al. identified RCTs at lowest risk of bias, where they found that studies assessing adherence "...generally involved complex interventions with multiple components, trying to overcome barriers to adherence by means of tailored ongoing support from allied health professionals such as pharmacists, who often delivered intense education, counseling (including motivational interviewing or cognitive behavioral therapy by professionals) or daily treatment support (or both), and sometimes additional support from family or peers (Nieuwlaat et al., 2014). However, as noted but the authors, these interventions did not lead to large improvements in adherence or clinical outcomes.

Perhaps most important in any study of adherence is to first properly operationalize how this outcome is measured. In a recent review by Anderson et al., the authors identified 25 high quality systematic reviews (with a mean of 36 primary studies) assessing interventions to improve medication adherence (Anderson et al., 2020). Overall it was found that $96 \%$ of these reviews did not restrict the method for measuring medication adherence, where the main outcomes of adherence were the following: $84 \%$ of reviews had at least one primary study that employed electronic monitoring to measure adherence (e.g., mobile text messaging, pill bottles with alarm features, etc.), $84 \%$ of reviews had at least one primary study that used fill count or had at least one primary study that used patient self-report, whereas, $68 \%$ had at least one primary study that used pharmacy refill data, and $8 \%$ had at least one primary study that used patient blood levels. Overall, it was determined that the top three measures that led to improvements in adherence were: dose simplification (5 systematic reviews), electronic reminders (4 systematic reviews), and patient education (4 systematic review).

Taken together, and with the understanding that medication adherence is best promoted with the aid of health professionals such as pharmacists, findings highlighted in this section demonstrate that interventions that focus on dose simplification-with tailored ongoing support-are the most successful in improving patient outcomes for adherence (Wilhelmsen and Eriksson, 2019). For these reasons, and for the fact that pictograms have been used for many years to improve patient information concerning their medications, the following sections will discuss the potential role of pictograms in 

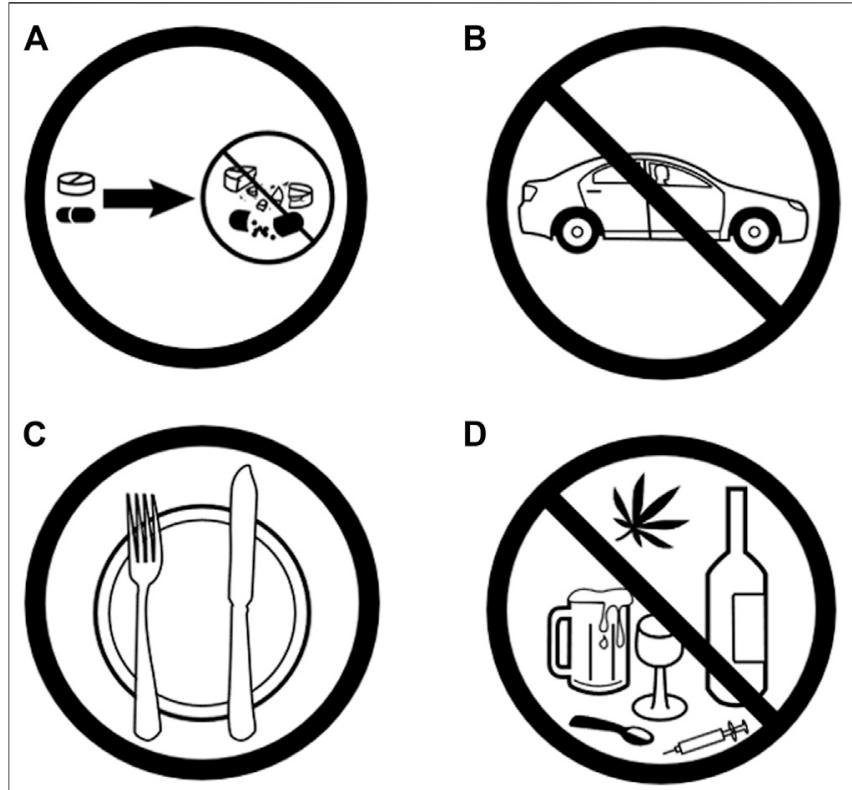

FIGURE 1 | Sample examples of pictograms used in pharmaceutical care: (A) Do not crush; (B) Do not drive; (C) Take with food; (D) Do not take with alcohol or drugs. Source: https://www.fipfoundation.org/.

improving medication adherence, with a focus on chronic patients.

\section{WHAT IS A PICTOGRAM?}

In general, pictograms are symbols or drawings representing a concept or idea (Peregrin, 2010). A pictogram should be considered as a two-part construct: a graphical symbol and its intended meaning. The "theory of semiotics" by Saussure introduces the distinction between the signifier (physical description of the object) and signified (its mental concept created by cultural convention) (Yang and Hsu, 2015), and importantly, the signified can have different meanings based on different cultures (Cloutier et al., 2014; Kheir et al., 2014). According to Dowse and Ehlers, "Well-designed pictograms should be simple and clear and able to convey their intended meaning to all patients, including those who are illiterate, elderly, or visually impaired." (Dowse et al., 1998). The guiding theory of pictogram use in any field of study is that when exposed to an image, the verbal memory may be triggered by reinforcing memory traces and subsequent recall; in order to do so, the message needs to be clear, appropriate for the intended audience, and must focus on actions rather than information (see Figure 1 for examples of validated pictograms for medication counselling). Furthermore, it is important to note that pictograms should be used in combination with traditional counselling/education. Specifically, prior patient counseling by pharmacists on the intended meaning and use of pictograms has been shown to improve the pictogram effectiveness (Ngoh, 2009), a fact that has been reiterated by (Montagne, 2013) in their description of best practices for the development and assessment of pictograms (Montagne, 2013).

\section{Pictograms in Health-Related Research: A Focus on Chronic Patients}

Why should healthcare providers consider using pictograms to convey health-related information during patient counselling? It has been reported that more than two-thirds of physicians provide written patient education materials for chronic patients (Carrier and Reschovsky, 2009), and between 40 and $80 \%$ of verbal information communicated during a health care consultation can be forgotten almost immediately (Kessels, 2003). Introduction of this review has already painted a picture of an epidemic of poor literacy, and despite abysmal worldwide levels of health literacy, the reading level of most health literature is above eighth grade (Cotugna et al., 2005), signifying a disparity between knowledge transfer. There is a sufficient body of evidence to show that pictograms not only make complicated patient information more attractive (Houts et al., 2006), but these images can also improve comprehension and recall of proper medication-taking behavior (Chan et al., 2015; Sletvold et al., 2020). Although the data on literacy and pictogram effectiveness is scant, results remain equivocal, where some groups have shown no impact where caregivers had adequate levels of literacy (Yin et al., 2011), whereas others have shown low and high literacy caregivers can both benefit from pictogram-based counselling (Hu et al., 2013; Tork, 2013).

There is a paucity of information on the use of pictograms in chronic patients to aid in medication adherence; however, one can see in Table 1 that the majority of studies in chronic patients are in patients living with HIV/AIDS. Although each study showed a positive outcome for the effectiveness of pictograms to improve recall and comprehension of dosing instructions, it was noted in a systematic review by Chan et al. that these are all studies with high risk of bias (Chan et al., 2015).

As seen in Table 1, there were several underlying themes that emerged in these interventions that deployed pictograms: the impact on pharmacotherapy safety, patient awareness and improvement of treatment results, patient involvement in the therapeutic process, and patient communication and trust in the delivery of their healthcare. It is worthwhile to note that a recent systematic review by Nguyen et al. identified at least 43 validated self-report adherence scales (Nguyen et al., 2014), indicating that it is crucial to consider the tool being used to assess the outcome of adherence, as well as the quality of the pictograms being tested. Overall, there is no single measure that can assess all the behaviors involved in being adherent to medication(s) and how this can impact patient outcomes. Selecting two (or more) medication adherence measures such as can be seen in Table 1 can allow strengths of one method (indirect methods of verbally explaining medication instructions) to help compensate putative weakness and to more accurately capture the information needed to determine adherence levels when incorporating another method (such as pictograms).

In patients living with chronic illness, data suggests that individuals with low health literacy can benefit more from 
TABLE 1 | Pictograms in the pharmaceutical care of chronically ill patients.

Study N $\quad \begin{gathered}\text { Study setting and } \\ \text { population characteristic }\end{gathered}$

Asthma

Almomani et al. $219 \bullet$ Jordan

(2018)

Wrench et al.

(2019)

- Patients from a rural primary healthcare clinic, dependent on the public healthcare sector, with a diagnosis of asthma, prescribed an MDI for at least 1 month, speaking either English or isiXhosa

- $\geq 18$ years of age

- Patients from an outpatient hospital pharmacy, with a diagnosis of bronchial used an inhaler device regularly for at least 3 months

- $\geq 18$ years of age
- Randomised, controlled trial

- Control: Verbal consultation only

- Assessment at baseline and after 3 months, evaluating the inhaler techniques with a standard checklist

- Pre-post intervention study

- Intervention: a Structured assessment of inhaler technique with the use of a 12-step checklist and a demonstration and patient education of the correct inhaler technique supported and facilitated by the illustrated study leaflet on MDI use (English or isiXhosa version)

- The intervention process was repeated 4 weeks later
- A statistically significant difference between the two groups regarding improvement in inhaler techniques after 3 months was observed for 2/4 devices: Metered dose inhaler (MDI) $(p<0.001)$ and turbohaler $(p=$ 0.005)

- Patients from the intervention group who used MDI and turbohaler were 7 and 5 times more likely to have improved their inhaler techniques as compared to the control group, respectively

- All intervention patients were satisfied with pictogram medals

- No significant differences in other asthma related clinical outcomes such as adherence to medication, asthma control, or unscheduled medical intervention was observed between the two groups at study end

- A statistically significant increase in the mean number of correct steps was observed: $4.6 \pm 2.2$ at baseline and $7.9 \pm$ 2.7 at follow-up $(p<0.05)$

- Statistically significant improvement of correct technique was observed in 10/12 steps controlled in the checklist

- All except one patient enjoyed the study pictograms

\section{Diabetes}

Doucette et al.

(2014)
- Pre-post intervention study

- Patients from of primary care physicians' offices under the auspices of the Regional Health Authority's Diabetes Education Centre diagnosed with type 2 diabetes mellitus

- 18-85 years of age
- Intervention: Patients were shown pictograms relating to diabetes complications, prevention, and treatment: "heart disease and stroke" ( $n=8)$ and pictograms relating to "nerve damage' ( $n=$ 7). Assessment of the pictogram meaning was made with a structured interview tool. Correct answers were recorded. Incorrect answers lead to patient education

- A follow-up assessment of the recall of pictograms was planned within 8 weeks. The number of correct responses was recorded
- High interpretation of each of the 8 "heart disease and stroke" pictograms (85\% or higher) for initial and follow-up interviews was noted

- Correct interpretation of $28.6 \%$ (2/7) of "nerve damage" pictograms during the initial interview and 100\% during the followup interview

- Overall, correct pictogram interpretation was significantly higher at the second interview (94.9 vs 82.8\%; 12.2\% difference; 95\% confidence interval [Cl], 4.7-19.7; $p<$ 0.003)

- A significant improvement in interpretation of the individual pictograms at the second interview was noted for two of the pictograms "pain medication" and "slow digestion".

- Among 13 participants who assessed their satisfaction with the pictograms, 11

(Continued on following page) 
TABLE 1 | (Continued) Pictograms in the pharmaceutical care of chronically ill patients.

\begin{tabular}{|c|c|c|c|c|}
\hline Study & $\mathbf{N}$ & $\begin{array}{c}\text { Study setting and } \\
\text { population characteristic }\end{array}$ & Methods and interventions & Result \\
\hline
\end{tabular}

\section{Chan and \\ 110 - Malaysia \\ Hassali, (2014) \\ - Patients from outpatient pharmacy in a major general hospital with refill prescriptions of selected oral antihypertensive or antidiabetic drugs}

\section{Mohan et al. $\quad 200 \quad$ U United States}

(2014)
- Randomised, controlled trial

- Intervention 1: font-enlarged labels

- Intervention 2: pictogram-enriched labels

- Control: Standard labels, or pictogram-

- Randomized, controlled trial

Negarandeh et al. 127 • Iran

(2013)
- Patients from a safety net clinic in Nashville, TN in a predominantly Spanish-speaking area. Patients were eligible if they were Latino, at least 18 years old, had a diagnosis of diabetes, and were prescribed at least 1 chronic medication

- Patients were excluded if they could not locate their medications or had a visual acuity $>20 / 50$, had hearing deficit, dementia, psychosis, disorientation, unable to communicate in English or Spanish, lacked a regular phone number, or belonged to a special population (e.g. pregnant or prisoner)

- $59 \%$ of patients had low health literacy tested by BHLS (Brief Health Literacy Screen)

- $71 \%$ of patients had not graduated high school

- Intervention: A PictureRx illustrated medication list depicted the medication, indication, and dosing instructions accompanied by plain-language bilingual text

- Control: Usual care, where patients received a written list of their medications in their preferred language, with indication but no images

- Outcomes were assessed by telephone 1 week later. The Medication Understanding Questionnaire was used to assess the patient's ability to report indication, strength, dosing and frequency for their medication regimen

- Secondary outcomes assessed were selfMedication adherence was assessed by the Adherence to Refills and Medications Scale (ARMS)

- Randomized, controlled trial

- Patients recruited from a secondary level diabetes clinic in Saqqez, Kurdistan with a diagnosis of type 2 diabetes for more than 6 months and had low health literacy (defined by a score of 59 or lower on TOFHLA), were at least 18 years old, and had no visual, mental, or learning disabilities

- Intervention 1: Education based on a teachback strategy during three weekly sessions lasting 20 min each. The patient also received written instructions of important information incorporated labels

- Assessment of baseline adherence comprehension, and preferences was conducted upon recruitment; follow-up telephone interviews - after 4 weeks reported adherence and satisfaction.

(84.6\%) were satisfied and 2 (15.4\%) were neutral

- All 3 groups demonstrated within-group increase of total adherence score after 4 weeks

- Total comprehension score of pictogramincorporated label group was significantly higher after 4 weeks (mean change 0.37, $p=0.010$ )

- Significantly higher scores for a few items in both adherence and comprehension measurements after 4 weeks were observed in the two intervention groups

- F tests indicated that all 3 groups did not significantly differ in the changes of both total adherence and comprehension scores ( $p=0.573$ and 0.069 , respectively) when subjects' age was adjusted

- Pictogram-incorporated labels over fontenlarged labels were preferred by the elderly and those with a higher number of morbidities

- Patients in the PictureRx group had an overall better understanding of their medications (MUQ difference 9.9; 95\% Cl 5.7-14.2; $p<0.01$ )

- Each point increase in BHLS was associated with an increase of 1.1 in MUQ overall score (95\% Cl 0.3-2.0)

- Self-reported adherence was 0.5 points higher in ARMS score $n$ the intervention group, though not statistically significant (95\% Cl, $-0.1-1.1)$

- Patients who received the PictureRx intervention reported very high satisfaction. 99\% reported that the tool was easy clear, easy to read, and helped them remember which medicines to take (96.9\%) and when to take them (96.9\%)

- Mean scores of knowledge, adherence to medication and adherence to dietary regimen were significantly higher in both intervention groups compared to control $(p<0.05)$
- There were no significant differences in knowledge or adherence between the two intervention groups 
TABLE 1 | (Continued) Pictograms in the pharmaceutical care of chronically ill patients.

\begin{tabular}{|c|c|c|c|c|}
\hline Study & $\mathbf{N}$ & $\begin{array}{c}\text { Study setting and } \\
\text { population characteristic }\end{array}$ & Methods and interventions & Result \\
\hline & & $\begin{array}{l}\text { - Patients were excluded if they had } \\
\text { participated in previous diabetes education } \\
\text { research }\end{array}$ & $\begin{array}{l}\text { - Intervention 2: Patients received education } \\
\text { with illustrated content during three weekly } \\
\text { sessions lasting } 20 \text { min each } \\
\text { - Control: Patients received usual care which } \\
\text { involved diabetes education presented in a } \\
\text { brochure. Questions were answered by a } \\
\text { community health nurse, similarly to the } \\
\text { intervention groups }\end{array}$ & \\
\hline
\end{tabular}

\section{AIDS}

Mansoor and

Dowse, (2006)

120 - South Africa

- Randomised, controlled trial

- Patients from local primary healthcare outpatient clinics, HIV-positive patients on chronic cotrimoxazole therapy, from a variety of educational backgrounds, able to read and understand either English or isiXhosa

- > 16 years of age

Mansoor and

Dowse, (2007)

Wilby et al. (2011)

- Canada

- Patients from an ambulatory pharmacy, HIV-positive patients who are receiving a new prescription for an antiretroviral medication

- $\geq 19$ years of age

Kalichman et al. $\quad 446$ - United States (2013)
- Two different PILs were designed for cotrimoxazole tablets and were available in both English and isiXhosa

- Intervention 1: Longer text-only PIL

- Intervention 2: Simple PIL with pictograms

- Control: No PIL

- Adherence to therapy was assessed using two methods: Self-report and tablet count $\sim 14$ days later

- Randomised, controlled trial

- Intervention 1: Text-only PIL, longer and more complex

- Intervention 2: a simple, shorter PIL that incorporated pictograms and text

- Control: No PIL

- Medicines knowledge was investigated in an interview 14 days later

- Randomised, controlled trial

- Intervention: pictogram-enhanced information

- Control: Standard counselling

- Evaluation of recall at first follow-up visit

- Evaluation of the recall at the next follow-up appointment at the ambulatory pharmacy

- Correct/incorrect response were recorded

- Randomized clinical trial
- In the group receiving materials incorporating simple text and pictograms a significant increase in adherence to therapy was noted, whereas a non-significant increase in adherence was observed in the group receiving more complex information (measured both by the self-report and the tablet count)

- Combined results from the self-report and tablet count found that the overall mean percentage adherence of the participants receiving Intervention 2 (88.3\%) was significantly higher than those receiving Intervention 1 (73.6\%), and the control group $(67.7 \%)(p<0.05)$

- Significantly more participants receiving Intervention 2 (92.5\%) obtained 100\% adherence when compared with the control group (70.0\%) $(p<0.05)$

- The results from the tablet count showed that the mean percentage adherence was significantly higher in participants who received Intervention 2 (86.5\%) when compared with the controls $(65.1 \%)$ or Intervention 1 (70.1\%) $(p<0.05)$

- The mean percentage for knowledge of medicines was significantly higher in the group that received the simple PIL incorporating pictograms (76.3\%), compared with both the control group (43.3\%) and the group who received the longer, text-only PIL (50.9\%) $(p<0.05)$

- Majority of the targeted pieces of information (88\%) in the intervention group were correctly identified at follow-up, while only $2 \%$ in the controls $(p<0.0001)$

- Majority of the intervention patients (79\%) recalled properly all targeted information versus none of patients in the control group $(p<0.0001)$

- The results were dependent of the fact that each pictogram was explained to patients prior to use

- Participants with marginal health literacy receiving Intervention 1 and Intervention 2 demonstrated greater adherence and (Continued on following page) 
TABLE 1 | (Continued) Pictograms in the pharmaceutical care of chronically ill patients

$\begin{array}{lll}\text { Study } & \text { Study setting and } & \text { Methods and interventions } \\ \text { population characteristic }\end{array}$

- Patients from AIDS services and community outreach, with HIV and receiving antiretroviral therapy, with marginal and lower health literacy levels

Dowse et al. $\quad 116$ - South Africa

Dowse
(2014)
- United States

- Patients from the johns Hopkins HIV clinic, patients with HIV and diabetes and/or hypertension attending a clinic for underserved patients and those at risk for poor health outcomes

- Patients using the HIV clinic pharmacy for all prescriptions, being prescribed medications for HIV and diabetes and/or hypertension for $\geq 6$ months, and being prescribed $\geq 5$ different medications per day total (for any condition); speaking English

- $\geq 18$ years of age
- Intervention 1: Pictograph-guided adherence counselling

- Intervention 2: Standard adherence counselling

- Control: general health improvement counselling

- Unannounced assessment: pill count adherence and blood plasma viral load 9months post-intervention

- Randomised, controlled study

- Intervention: Standard care plus simple pretested PIL containing both text and illustrations

- Control: Standard care

- HIV and medicines-related knowledge was evaluated at baseline, one, three, and 6 months post-intervention; self-efficacy was assessed over 6 months

- Randomized controlled study

- Intervention: Pictorial aid: a photographic representation of the medications, the indications, and the dosing schedule

- Control: Standard clinic visit discharge medication list

- Assessment of the adherence to antiretroviral therapy (ART) for HIV and therapy for diabetes or hypertension was compared undetectable HIV viral loads compared to controls

- Participants with lower health literacy skills in the control group demonstrated greater adherence compared to the two adherence counselling groups

- Intervention patients presented a significant knowledge increase over the 6-month period (62.0-94.4\%), and an improvement at each subsequent interview was noted. No improvement was observed in the control group

- Side effect knowledge, which was the lowest (50-56\%) at baseline increased in the intervention group to $92 \%$

- Other medicine-related knowledge at baseline (57-67\%) improved significantly (93\%), which was sustained over 6 months

- A large intervention effect was observed (Cohen's d values post-baseline were 1.36-2.18)

- A significant improvement over 6 months in self-efficacy was observed in the intervention group but not in controls

- At baseline, patients with $\leq 3$ years of education had lower knowledge and selfefficacy. However, this was not reported post-intervention, which was attributed by the authors to the PIL mitigating the limited education effect

- In the intervention group knowledge and self-efficacy were significantly correlated

- There was a trend towards higher adherence to medications for HIV as compared with hypertension/diabetes medications ( $p=0.07$ )

- The intervention was feasible to implement and satisfaction with the intervention was high 
TABLE 1 | (Continued) Pictograms in the pharmaceutical care of chronically ill patients.

\begin{tabular}{|c|c|c|c|c|}
\hline Study & $\mathbf{N}$ & $\begin{array}{c}\text { Study setting and } \\
\text { population characteristic }\end{array}$ & Methods and interventions & Result \\
\hline $\begin{array}{l}\text { Browne et al. } \\
\text { (2019) }\end{array}$ & 116 & $\begin{array}{l}\text { - South Africa } \\
\text { - Patients from local public sector clinics, HIV } \\
\text { patients taking antiretroviral drugs, patients } \\
\text { with limited literacy, isiXhosa-speaking }\end{array}$ & $\begin{array}{l}\text { - Randomised, controlled study } \\
\text { - Intervention: Standard care plus illustrated } \\
\text { information: Side-effect pictograms, } \\
\text { combined with simple text, incorporated into } \\
\text { a side effects panel within an ARV } \\
\text { information leaflet } \\
\text { - Control: Standard care } \\
\text { - Side-effect knowledge was assessed at } \\
\text { baseline. Interpretation of side-effect } \\
\text { pictograms was evaluated after } 1 \text { month. } \\
\text { Knowledge was re-tested after one and } \\
3 \text { months }\end{array}$ & $\begin{array}{l}\text { - The mean side effect knowledge increased } \\
\text { from } 45.9 \% \text { (baseline) to 95.7\% (after } \\
3 \text { months) in the intervention group ( } p< \\
0.0001 \text { ) } \\
\text { - Knowledge did not change significantly in } \\
\text { the control group } \\
\text { - Pictogram interpretation was good } \\
\text { - All patients found the pictograms clear and } \\
\text { useful, and endorsed their routine use }\end{array}$ \\
\hline
\end{tabular}

\section{Chronic kidney Disease}

\begin{tabular}{|c|c|c|}
\hline $\begin{array}{l}\text { Mateti et al. } \\
(2015)\end{array}$ & 81 & $\begin{array}{l}\text { - India } \\
\text { - Patients from haemodialysis (HD) units of } \\
\text { academic, government, and corporate } \\
\text { hospitals, HD patients on pharmaceutical } \\
\text { care group with minimum primary } \\
\text { educational background, patients } \\
\text { undergoing HD continuously for } 3 \text { months } \\
\text { - } 18-75 \text { years of age }\end{array}$ \\
\hline \multicolumn{3}{|c|}{ Cardiac disorders } \\
\hline $\begin{array}{l}\text { Zerafa et al. } \\
\text { (2011) }\end{array}$ & 80 & - Malta \\
\hline
\end{tabular}

- Patients who underwent coronary artery bypass or heart valve surgery at the cardiac Surgical Ward and Medical outpatients clinic of Mater Dei Hospital, Birkirkara, Malta, able to communicate with the investigator; mentally competent

- $>18$ years of age

Kripalani et al. $\quad 435$ - United States (2012)
- Quasi-experimental pre- and post-test

- Without control group

- Usability testing of the pictogram-based PILs

- Randomised, controlled trial (although called a case-controlled study in the manuscript)

- Intervention: a chart with pictorial explanation of the time of day together with a colourful photograph of each tablet prescribed and counselled to comply to oral analgesia and exercise and also on the avoidance of alcohol and smoking during the recovery period

- Control: Usual care without the pharmacist intervention

- All patients were re-interviewed 8 weeks after discharge

- Randomised, controlled trial

- Patients from an inner-city primary care clinic, adults with coronary heart disease reminder postcards, illustrated medication
- $2 \times 2$ factorial design: Usual care, refill, schedules, or both interventions for 1 year

- Cardiovascular medication refill adherence was assessed by the cumulative medication gap (CMG)
- The overall user testing knowledge assessment mean scores significantly improved from 44.25 to 69.62 ( $p<0.001)$
- Patients in the intervention group had a higher mean percentage compliance score $(88 \%)$ than the controls $(66 \%)(p<0.05)$
- Among those that $\mathrm{CMG}$ could be calculated 138 (32.9\%) had $\mathrm{CMG}<0.20$ during follow-up and were considered adherent

- Overall, adherence rate did not differ significantly across treatments: $31.2 \%$ in usual care, $28.3 \%$ with mailed refill reminders, $34.2 \%$ with illustrated medication schedules, and $36.9 \%$ with both interventions

- In post-hoc analyses, illustrated medication schedules were found to led to significantly greater odds of adherence among patients who at baseline had $>8$ medications $(\mathrm{OR}=$ 2.2; 95\% Cl, 1.21-4.04) or low self-efficacy for managing medications (OR $=2.15$; $95 \%$ Cl, 1.11-4.16); a trend was found among patients who reported non-adherence at baseline $(\mathrm{OR}=1.89$; 95\% Cl, 0.99-3.60) (Continued on following page) 
TABLE 1 | (Continued) Pictograms in the pharmaceutical care of chronically ill patients.

\begin{tabular}{|c|c|c|c|c|}
\hline Study & $\mathbf{N}$ & $\begin{array}{c}\text { Study setting and } \\
\text { population characteristic }\end{array}$ & Methods and interventions & Result \\
\hline $\begin{array}{l}\text { Hawkins and } \\
\text { Firek, (2014) }\end{array}$ & 27 & $\begin{array}{l}\text { - United States } \\
\text { - Patients from a large Veterans' } \\
\text { Administration facility in southern California } \\
\text { who presented to the VA outpatient heart } \\
\text { failure clinic, with congestive heart failure } \\
\text { (CHF) and cognitive impairment } \\
\text { - Participants } 18 \text { years old or older, had a } \\
\text { diagnosis of CHF, and screened positive for } \\
\text { cognitive impairment using the Saint Louis } \\
\text { University Mental Status (SLUMS) exam } \\
\text { - Patients excluded if they had severe } \\
\text { functional limitations, acutely } \\
\text { decompensated CHF, dementia requiring a } \\
\text { caregiver, severe mental illness such as } \\
\text { schizophrenia, or a life expectancy of less } \\
\text { than } 6 \text { months }\end{array}$ & $\begin{array}{l}\text { - Crossover study } \\
\text { - Pre-intervention: Subjects brought their } \\
\text { prescribed medications for a pill count, and } \\
\text { returned after } 30 \text { days for a repeat pill count } \\
\text { to assess baseline adherence } \\
\text { - Post-intervention: customized pictorial } \\
\text { medication sheet with brief instructions on } \\
\text { use, and optional CADEX Pocket Pill Box } \\
\text { with vibrating alarms. Pictorial medication } \\
\text { sheets included images on the participant's } \\
\text { current medications printed in full colour and } \\
\text { dose range, arranged in columns for } \\
\text { morning, noon, and evening. A brief } \\
\text { description of the medication name, } \\
\text { indication, and dose were included. Pill } \\
\text { count was assessed after } 30 \text { and } 60 \text { days }\end{array}$ & $\begin{array}{l}\text { - Patients medication adherence significantly } \\
\text { improved from pre-intervention to post- } \\
\text { intervention ( }(26)=2.16, p<0.05 \text { ) } \\
\text { - Patient acceptance of the intervention was } \\
\text { high, with } 74.1 \% \text { of participants indicating } \\
\text { the medication sheet was very helpful in } \\
\text { remembering to take medications and filling } \\
\text { medication boxes }\end{array}$ \\
\hline $\begin{array}{l}\text { Machtinger et al. } \\
(2007)\end{array}$ & 147 & $\begin{array}{l}\text { - Patients from a pharmacist-staffed } \\
\text { anticoagulation clinic at San Francisco } \\
\text { General Hospital (SFGH) receiving chronic } \\
\text { warfarin } \\
\text { - At least } 18 \text { years old, spoke English, } \\
\text { Spanish or Cantonese, were taking warfarin } \\
\text { for at least } 3 \text { months, had an INR outside the } \\
\text { therapeutic range (either } 2.0-3.0 \text { or } 2.5-3.5) \\
\text { within } 5 \text { days prior to enrolment } \\
\text { - Patients excluded if they had a psychiatric } \\
\text { disorder, dementia, blindness, aphasia, } \\
\text { were too ill to participate, could not } \\
\text { communicate independently, had corrected } \\
\text { vision of } 20 / 100 \text { or worse, used pill boxes } \\
\text { filled by health care professionals, managed } \\
\text { their warfarin by telephone, expected to } \\
\text { stop taking warfarin within } 90 \text { days, or were } \\
\text { not using warfarin preparations on the } \\
\text { SFGH formulary }\end{array}$ & $\begin{array}{l}\text { - Randomized, controlled trial } \\
\text { - Intervention: Visual medication schedule at } \\
\text { each visit with digitized images of the } \\
\text { patient's warfarin regimen printed on a } \\
\text { weeklong calendar, plus standard care } \\
\text { - Control: Standard care, which included } \\
\text { standard medication counselling and follow- } \\
\text { up in the anticoagulation clinic and } \\
\text { consultation and medication management } \\
\text { by pharmacists with expertise in } \\
\text { anticoagulation }\end{array}$ & $\begin{array}{l}\text { - Intervention subjects achieved } \\
\text { anticoagulation control more rapidly than } \\
\text { control subjects (median } 28 \text { vs } 42 \text { days; } \\
\text { hazard ratio [HR] 1.43; } \mathrm{Cl} 1.00,2.06 \text { ) } \\
\text { - The intervention showed significant benefit } \\
\text { in subjects with baseline regimen } \\
\text { discordance (median } 28 \text { vs } 49 \text { days; HR } \\
\text { 1.92; } \mathrm{Cl} 1.08,3.39 \text { ) but the benefit was not } \\
\text { significant among subjects with baseline } \\
\text { concordance (median } 28 \text { vs } 35 \text { days; HR } \\
\text { 1.14; } \mathrm{Cl} 0.71-1.83 \text { ) }\end{array}$ \\
\hline
\end{tabular}

TOFHLA, Test of Functional Health Literacy in Adults.

interventions employing pictograms (Machtinger et al., 2007; Negarandeh et al., 2013; Mohan et al., 2014; Phimarn et al., 2019), whereas, individuals with high health literacy do not seem to benefit to the same degree (Kripalani et al., 2012). Table 1 summarizes the results of studies on the use of pictograms among chronically ill patients in distinction for the following diseases: asthma $(n=2)$, diabetes $(n=4)$, AIDS $(n=7)$, chronic kidney disease $(n=1)$, and cardiac disorders $(n=4)$. Studies focusing on the elderly were analyzed separately $(n=3)$. Studies focusing on self-efficacy were analyzed separately $(n=2)$. The data obtained in the selected studies indicate that the use of pictograms significantly increased various aspects of disease self-management of the patients with chronic conditions. However, not all pictogram interventions were found to be effective, where several groups have failed to find a significant effect of pictograms in helping with medication adherence in patients living with chronic illness (Kripalani et al., 2012; Advani et al., 2013; Chan and Hassali, 2014).

In our work, apart from comprehensive review on the impact of pictograms on adherence in chronically ill patients, we also would like to point out some methodological issues, which may be an obstacle to a reliable assessment of the impact of pictograms on adherence.

Publications summarize in Table $\mathbf{1}$ describes the role of pictograms in chronically ill patients, but from methodological point of view, they are different in many respects. First of all, the results were obtained in many different countries and among subjects with different level of literacy. As we stated previously these factors can have a considerable impact on the usefulness and efficacy of pictograms. Additionally to this, interventions were carried out in patients with different chronic diseases. 
Moreover, the number of patients participating in assessing studies varied a lot $(n=17-446)$. Apart from that, these studies lacked information of the clarity and appropriateness of pictograms chosen. There was also a lack of explanations on the validity and reliability of instruments used. One should also pay attention to the differences in the methods of patient education. Interventions described in cited publications were carried out both in pharmacies and clinics, so we can anticipate many differences in approach to education as well as the amount of time devoted to the patient.

These all above described factors impact on heterogenicity of published trials and consequently have an impact on the possibility of comparing obtained results, drawing conclusions and preparing more credible publications like metanalysis. Future research should also devote more attention to aforementioned limitations of the included studies. Maybe good tool, which can contribute to overcome these methodological problems is developing specific protocols that will be used in further studies. That protocols could allow collect more coherent results and precise assessment of the impact of pictograms on adherence.

\section{Importance of Pictogram Design and Evaluation: Fundamental Concepts, Issues, and Problems}

\section{Best Practices in Pictogram Design}

Pictograms, when properly designed and validated, have been implemented to help convey medication information in many health-related settings and humanitarian missions (e.g., hospitals, pharmacies, temporary aid stations, etc.) with varying degrees of successful outcomes (Houts et al., 2006; Sorfleet et al., 2009; Dowse et al., 2014). But in order to make any conclusions on the effectiveness of pictograms on medication adherence, and prior to having to consider how to answer a research question with a large and expensive randomized trial, one first needs to be sure the image meets specific standards of best practice in pictogram design.

Researchers in the field of health-related pictograms should consider the following. First, and most important to ensuring best practices are being followed, is the rigorous and time consuming process of designing new pictograms. Pictograms must go through a systematic design process, whereby images are piloted and tested on scales of transparency (or "guessability of meaning") and translucency ("agreeability of intended meaning"), each of which contribute to independent elements that come together to determine the overall comprehensibility of the pictogram (Vaillancourt et al., 2017), which can also be evaluated with open choice face-to-face methods (Mansoor and Dowse, 2003). It is important to note that there are differences in patient populations to consider (e.g., education, beliefs, attitudes, etc.) in this initial process of testing and design (Dowse and Ehlers, 2003). In particular, many studies have now demonstrated the importance of considering differences in pictorial interpretation between countries, and several studies have also demonstrated cultural differences within countries, and these differences can determine whether the information relayed in the pictogram is correctly understood (Doak et al., 1996; Ehlers et al., 2004; Grenier et al., 2011). As such, if the researcher is to ensure an effective evaluation process for pictogram design that can provide data that is both valid and reliable, it is integral to have the target population involved at all stages of the design process.

Furthermore, in order to be able to systematically evaluate differences in study outcomes in the field of health-related pictogram research there are several other important elements to consider to ensure that best practices in pictogram design are followed (for extensive details see: Dowse, 2020; Abdullah et al., 2006; Mansoor and Dowse, 2004). These are guiding documents that should serve to help groups in health-related research to produce high quality pictograms with optimal legibility and visibility. Sletvold et al. (2020) concluded that studies assessing the value of pharmaceutical pictograms must establish best practices in the design and use of pictograms to ensure we can isolate the independent effects of pictograms on medication adherence (Sletvold et al., 2020).

\section{Best Practices in Pictogram Evaluation}

An important consideration for the successful evaluation of pictograms in the delivery of health information is to ensure that the healthcare professionals who will ultimately deliver the education and counselling are involved in the entire process of design and evaluation. For example, when implementing pharmaceutical pictograms that help with medication adherence, patients generally still need to be taught how to interpret the pictograms (Ngoh, 2009), and these increased task demands on the pharmacist must be perceived as a beneficial use of time and resources in order to get the most benefit for the patient. Much research in the study of pictograms in the field of health information-and in particular research on medication adherence-still does not explicitly specify if pharmacists were involved in the design or implementation of the specific pictogram intervention. Results described by Wilhelmsen \& Eriksson (2019) in a recent systematic review possibly speak to this importance, where they noted: “. . that interventions delivered by pharmacists and nurses showed a better result in improving adherence and outcomes than interventions delivered by general practitioners (Wilhelmsen and Eriksson, 2019). Although this is not direct evidence for the case, future research can benefit from a standardization process whereby these details are systematically documented, for example, when trials are registered. Finally, once best practices have been employed in the design and evaluation of the pharmaceutical pictograms, the research team is ready to design a randomized controlled trial that can isolate the independent effects of pictograms on, for example, medication adherence. As noted by (Anderson et al., 2020) systematic overview of systematic reviews, much of the research on medication adherence is highly heterogeneous in study designs, settings, and methods (Anderson et al., 2020), so attention must be focused on the fidelity of design to ensure reproducibility of the data. These summaries of fundamental problems were echoed by (Sletvod et al., 2020), where the authors concluded that heterogeneity in the design and conduct of the current landscape of RCTs examining pictograms in medication 
adherence preclude any meta-analysis of observed pictogram effects (Sletvold et al., 2020).

\section{CONCLUSIONS AND FUTURE PERSPECTIVES}

On the basis of the reviewed data, we conclude that effective spoken and written communication of information about medicine, in combination with health-related pictograms, can lead to improved treatment outcomes for the patient. Low health literacy levels negatively affect patients-including chronic patients-across the continuum of care. With this in mind, pharmacists and health care-providers are well-situated to ensure that patients adhere to their medication regimens correctly, especially so for lower health literacy populations. Chronically ill patients are a population that can benefit from interventions (e.g. "teach back" and Ask Me $3^{\mathrm{TM}}$ ) because their pharmacotherapy is often a life-long challenge, which often requires coping with complex daily multi-drug regimens that can require high levels of literacy and self-efficacy.

The current review highlighted adherence in chronic patients. Due to a paucity of research on pictograms and medication adherence in this population and due to the lack of best practice in much of the existing research, we could not conclude that these patients benefitted any more or less from pictogram interventions. Indeed, in the recent systematic review by Sletvold et al. (2020) the authors found a possible effect of pictograms on medication adherence, but in order to make

\section{REFERENCES}

Abdullah, R., Hübner, R., and Cziwerny, R. (2006). Pictograms, Icons \& Signs: A Guide to Information Graphics. W. W. Norton.

Ad Hoc Committee on Health Literacy for the Council on Scientific Affairs, American Medical Association (1999). Health Literacy. Report of the Council on Scientific Affairs. JAMA 281, 552-557. doi:10.1001/jama.281.6.552

Advani, A. A., Lopez, J., Jones, J., and Patel, S. (2013). The Role of Pictograms for Enhancement of Patient Prescription Medication Information in the US. J. Pharm. Technology 29, 40-45. doi:10.1177/875512251302900107

Allinson, M., and Chaar, B. (2016). How to Build and Maintain Trust with Patients. Pharm. J. 297, 20201862, 2016 . Availableat: https://www.pharmaceuticaljournal.com/eye-care/how-to-build-and-maintain-trust-with-patients/ 20201862.article?firstPass=false (Accessed July 6, 2020).

Almomani, B. A., Mokhemer, E., Al-Sawalha, N. A., and Momany, S. M. (2018). A Novel Approach of Using Educational Pharmaceutical Pictogram for Improving Inhaler Techniques in Patients with Asthma. Respir. Med. 143, 103-108. doi:10.1016/j.rmed.2018.09.004

Anderson, L. J., Nuckols, T. K., Coles, C., Le, M. M., Schnipper, J. L., Shane, R., et al. (2020). A Systematic Overview of Systematic Reviews Evaluating Medication Adherence Interventions. Am. J. Health Syst. Pharm. 77, 138-147. doi:10.1093/ajhp/zxz284

Bailey, S. C., Brega, A. G., Crutchfield, T. M., Elasy, T., Herr, H., Kaphingst, K., et al. (2014). Update on Health Literacy and Diabetes. Diabetes Educ. 40 (5), 581-604. doi:10.1177/0145721714540220.Baker

Bains, S. S., and Egede, L. E. (2011). Associations between Health Literacy, Diabetes Knowledge, Self-Care Behaviors, and Glycemic Control in a Low Income Population with Type 2 Diabetes. Diabetes Technology Ther. 13, 335-341. doi:10.1089/dia.2010.0160

Baker, D. W. (2006). The Meaning and the Measure of Health Literacy. J. Gen. Intern. Med. 21, 878-883. doi:10.1111/j.1525-1497.2006.00540.x stronger conclusions, researchers in this field need to follow best practices not only in the design and evaluation of healthrelated pictograms, but also in the design of strong RCTs that can isolate the independent effects of pictograms on study outcomes (Sletvold et al., 2020). Taken together, research in the field of health-related pictograms and medication adherence should focus on creating content that focuses on dose simplification and electronic reminders. By adhering to best practices in the design, testing, and evaluation of pictograms, we can strengthen future findings from this exciting and visually stimulating field of health-related research.

\section{AUTHOR CONTRIBUTIONS}

Conceptualization, $\mathrm{PM}, \mathrm{KB}$, and $\mathrm{RV}$; methodology, RV; validation, MJ, and RV; formal analysis, TC, KB, PM, TH, KB, KS; investigation, PM; resources, DS; data curation, PM; writingoriginal draft preparation, $\mathrm{PM}$, JC, and RV; writing-review and editing, TC; visualization, MJ; supervision, RV; project administration, PM. All authors have read and agreed to the published version of the article.

\section{ACKNOWLEDGMENTS}

The Authors would like to thank to Polish Pharmaceutical Group for providing us with access to databases and Proper Medical Writing, Warsaw, Poland for editing and linguistic support.

Bandura, A. (1977). Self-efficacy: Toward a Unifying Theory of Behavioral Change. Psychol. Rev. 84, 191-215. doi:10.1037/0033-295X.84.2.191

Bann, C. M., McCormack, L. A., Berkman, N. D., and Squiers, L. B. (2012). The Health Literacy Skills Instrument: A 10-item Short Form. J. Health Commun. 17, 191-202. doi:10.1080/10810730.2012.718042

Berkman, N. D., Sheridan, S. L., Donahue, K. E., Halpern, D. J., and Crotty, K. (2011). Low Health Literacy and Health Outcomes: An Updated Systematic Review. Ann. Intern. Med. 155, 97-107. doi:10.7326/0003-4819-155-2-201107190-00005

Bostock, S., and Steptoe, A. (2012). Association between Low Functional Health Literacy and Mortality in Older Adults: Longitudinal Cohort Study. BMJ 344, e1602. doi:10.1136/bmj.e1602

Bröder, J., Chang, P., Kickbusch, I., Levin-Zamir, D., McElhinney, E., Nutbeam, D., et al. (2018). IUHPE Position Statement on Health Literacy: a Practical Vision for a Health Literate World. Glob. Health Promot. 25, 79-88. doi:10.1177/ 1757975918814421

Brown, M. T., Bussell, J., Dutta, S., Davis, K., Strong, S., and Mathew, S. (2016). Medication Adherence: Truth and Consequences. Am. J. Med. Sci. 351, 387-399. doi:10.1016/j.amjms.2016.01.010

Browne, S. H., Barford, K., Ramela, T., and Dowse, R. (2019). The Impact of Illustrated Side Effect Information on Understanding and Sustained Retention of Antiretroviral Side Effect Knowledge. Res. Soc. Administrative Pharm. 15, 469-473. doi:10.1016/j.sapharm.2018.05.012

Buttorff, C., Ruder, T., and Bauman, M. (2017). Multiple Chronic Conditions in the United States. Santa Monica, CA: RAND Corporation. doi:10.7249/tl221Availableat: https://www.rand.org/pubs/tools/TL221.html (Accessed July 6, 2020).

Canadian Council on Learning (2008). Health Literacy in Canada: A Healthy Understanding. Ottawa. Availableat: http://www.en.copian.ca/library/research/ $\mathrm{ccl} /$ health/health.pdf (Accessed July 6, 2020).

Carrier, E., and Reschovsky, J. (2009). Expectations Outpace Reality: Physicians' Use of Care Management Tools for Patients with Chronic Conditions. Issue. Brief. Cent. Stud. Health Syst. Change 129, 1-4. 
Centres for Disease Control and Prevention (2020). Chronic Disease Prevention and Health Promotion. Availableat: https://www.cdc.gov/chronicdisease/index. htm (Accessed July 6, 2020).

Chan, H.-K., and Hassali, M. A. (2014). Modified Labels for Long-Term Medications: Influences on Adherence, Comprehension and Preferences in Malaysia. Int. J. Clin. Pharm. 36, 904-913. doi:10.1007/s11096-014-0003-1

Chan, H. K., Hassali, M. A., Lim, C. J., Saleem, F., and Tan, W. L. (2015). Using Pictograms to Assist Caregivers in Liquid Medication Administration: a Systematic Review. J. Clin. Pharm. Ther. 40, 266-272. doi:10.1111/jcpt.12272

Chen, J. (1999). "Medication Concordance" Is Best Helped by Improving Consultation Skills. Bmj 318, 670. doi:10.1136/bmj.318.7184.670

Clark, J. M., and Paivio, A. (1991). Dual Coding Theory and Education. Educ. Psychol. Rev. 3, 149-210. doi:10.1007/BF01320076

Cloutier, M., Vaillancourt, R., Pynn, D., Wade, J., Preston, C., Turpin, P.-M., et al. (2014). Design and Development of Culture-specific Pictograms for Type 2 Diabetes Mellitus Education and Counselling. Can. J. Diabetes 38, 379-392. doi:10.1016/j.jcjd.2014.03.010

Cotugna, N., Vickery, C. E., and Carpenter-Haefele, K. M. (2005). Evaluation of Literacy Level of Patient Education Pages in Health-Related Journals. J. Community Health 30, 213-219. doi:10.1007/s10900-004-1959-x

Davis, T. C., Fredrickson, D. D., Potter, L., Brouillette, R., Bocchini, A. C., Williams, M. V., et al. (2006). Patient Understanding and Use of Oral Contraceptive Pills in a Southern Public Health Family Planning Clinic. South. Med. J. 99, 713-718. doi:10.1097/01.smj.0000223734.77882.b2

DeWalt, D. A., Berkman, N. D., Sheridan, S., Lohr, K. N., and Pignone, M. P. (2004). Literacy and Health Outcomes. J. Gen. Intern. Med. 19, 1228-1239. doi:10.1111/j.1525-1497.2004.40153.x

DeWalt, D. A., Broucksou, K. A., Hawk, V., Brach, C., Hink, A., Rudd, R., et al. (2011). Developing and Testing the Health Literacy Universal Precautions Toolkit. Nurs. Outlook 59, 85-94. doi:10.1016/j.outlook.2010.12.002

DeWalt, D. A., and Hink, A. (2009). Health Literacy and Child Health Outcomes: A Systematic Review of the Literature. Pediatrics 124, S265-S274. doi:10.1542/ peds.2009-1162B

DeWalt, D. A., Malone, R. M., Bryant, M. E., Kosnar, M. C., Corr, K. E., Rothman, R. L., et al. (2006). A Heart Failure Self-Management Program for Patients of All Literacy Levels: A Randomized, Controlled Trial [ISRCTN11535170]. BMC Health Serv. Res. 6. doi:10.1186/1472-6963-6-30

DiMatteo, M. R. (2004). Variations in Patients' Adherence to Medical Recommendations. Med. Care 42, 200-209. doi:10.2307/464072910.1097/ 01.mlr.0000114908.90348.f9

Doak, C. C., Doak, L. G., and Root, J. H. (1996). Teaching Patients with Low Literacy Skills. second ed. J. B. Lippincott.

Donovan, J. L. (1995). Patient Decision Making: The Missing Ingredient in Compliance Research. Int. J. Technol. Assess. Health Care 11, 443-455. doi:10.1017/S0266462300008667

Doucette, D., Vaillancourt, R., Berthenet, M., Li, L. S., and Pouliot, A. (2014). Validation of a Pictogram-Based Diabetes Education Tool in Counselling Patients with Type 2 Diabetes. Can. Pharm. J. 147, 340-344. doi:10.1177/1715163514552662

Dowse, R., Barford, K., and Browne, S. H. (2014). Simple, Illustrated Medicines Information Improves ARV Knowledge and Patient Self-Efficacy in Limited Literacy South African HIV Patients. AIDS Care 26, 1400-1406. doi:10.1080/09540121.2014.931559

Dowse, R. (2021). Designing and Reporting Pictogram Research: Problems, Pitfalls and Lessons Learnt. Res. Soc. Administrative Pharm. 17, 1208-1215. doi:10.1016/j.sapharm.2020.08.013

Dowse, R., and Ehlers, M. (2004). Pictograms for Conveying Medicine Instructions: Comprehension in Various South African Language Groups. South Afr. J. Sci. 100, 687-693.

Dowse, R., Ehlers, M. S., and Dowse, R. (2011). Pictograms in Pharmacy. Int. J. Pharm. Pract. 6, 109-118. doi:10.1111/j.2042-7174.1998.tb00924.x

Dowse, R., and Ehlers, M. S. (2010). The Influence of Education on the Interpretation of Pharmaceutical Pictograms for Communicating Medicine Instructions. Int. J. Pharm. Pract. 11, 11-18. doi:10.1211/002235702810

Dunbar-Jacob, J., and Mortimer-Stephens, M. K. (2001). Treatment Adherence in Chronic Disease. J. Clin. Epidemiol. 54 (Suppl. 1), 57-60. doi:10.1016/s08954356(01)00457-7

Farmer, K. C. (1999). Methods for Measuring and Monitoring Medication Regimen Adherence in Clinical Trials and Clinical Practice. Clin. Ther. 21, 1074-1090. doi:10.1016/S0149-2918(99)80026-5
Forsyth, A. D., and Carey, M. P. (1998). Measuring Self-Efficacy in the Context of HIV Risk Reduction: Research Challenges and Recommendations. Health Psychol. 17, 559-568. doi:10.1037/0278-6133.17.6.559

Gazmararian, J. A., Williams, M. V., Peel, J., and Baker, D. W. (2003). Health Literacy and Knowledge of Chronic Disease. Patient Education Couns. 51, 267-275. doi:10.1016/S0738-3991(02)00239-2

Graham, S., and Brookey, J. (2008). Do Patients Understand? permj 12, 67. doi:10.7812/TPP/07-144

Grenier, S., Vaillancourt, R., Pynn, D., Cloutier, M. C., Wade, J., Turpin, P. M., et al. (2011). Design and Development of Culture-specific Pictograms for the Labelling of Medication for First Nation Communities. J. Commun. Healthc. 4, 238-245. doi:10.1179/1753807611Y.0000000007

Hawkins, L. A., and Firek, C. J. (2014). Testing a Novel Pictorial Medication Sheet to Improve Adherence in Veterans with Heart Failure and Cognitive Impairment. Heart \& Lung 43, 486-493. doi:10.1016/j.hrtlng.2014.05.003

Haynes, R. B., Ackloo, E., Sahota, N., McDonald, H. P., and Yao, X. (2008). Interventions for Enhancing Medication Adherence. Cochrane Database Syst. Rev. 16, CD000011. doi:10.1002/14651858.CD000011.pub3

Hepler, C. D., and Strand, L. M. (1990). Opportunities and Responsibilities in Pharmaceutical Care. Am. J. Hosp. Pharm. 47, 533-543. doi:10.1093/ajhp/ 47.3.533

Houts, P. S., Doak, C. C., Doak, L. G., and Loscalzo, M. J. (2006). The Role of Pictures in Improving Health Communication: A Review of Research on Attention, Comprehension, Recall, and Adherence. Patient Education Couns. 61, 173-190. doi:10.1016/j.pec.2005.05.004

Hu, H., Wu, F.-L. L., Hu, F.-C., Yang, H.-Y., Lin, S.-W., and Shen, L.-J. (2013). Effectiveness of Education Programs about Oral Antibiotic Suspensions in Pediatric Outpatient Services. Pediatr. Neonatal. 54, 34-42. doi:10.1016/ j.pedneo.2012.10.002

Ingersoll, K. S., and Cohen, J. (2008). The Impact of Medication Regimen Factors on Adherence to Chronic Treatment: a Review of Literature. J. Behav. Med. 31, 213-224. doi:10.1007/s10865-007-9147-y

Iuga, A. O., and McGuire, M. J. (2014). Adherence and Health Care Costs. Risk Manag. Healthc. Pol. 7, 35-44. doi:10.2147/RMHP.S19801

Kalichman, S. C., Benotsch, E., Suarez, T., Catz, S., Miller, J., and Rompa, D. (2000). Health Literacy and Health-Related Knowledge Among Persons Living with HIV/AIDS. Am. J. Prev. Med. 18, 325-331. doi:10.1016/S07493797(00)00121-5

Kalichman, S. C., Cherry, C., Kalichman, M. O., Amaral, C., White, D., Grebler, T., et al. (2013). Randomized Clinical Trial of HIV Treatment Adherence Counseling Interventions for People Living with HIV and Limited Health Literacy. J. Acquir. Immune Defic. Syndr. 63, 42-50. doi:10.1097/QAI.0b013e318286ce49

Katz, M. G., Kripalani, S., and Weiss, B. D. (2006). Use of Pictorial Aids in Medication Instructions: A Review of the Literature. Am. J. Heal. Pharm. 63, 2391-2397. doi:10.2146/ajhp060162

Kessels, R. P. C. (2003). Patients' Memory for Medical Information. Jrsm 96, 219-222. doi:10.1258/jrsm.96.5.219

Kheir, N., Awaisu, A., Radoui, A., El Badawi, A., Jean, L., and Dowse, R. (2014). Development and Evaluation of Pictograms on Medication Labels for Patients with Limited Literacy Skills in a Culturally Diverse Multiethnic Population. Res. Soc. Administrative Pharm. 10, 720-730. doi:10.1016/j.sapharm.2013.11.003

Killian, L., and Coletti, M. (2017). The Role of Universal Health Literacy Precautions in Minimizing "Medspeak" and Promoting Shared Decision Making. AMA J. Ethics 19, 296-303. doi:10.1001/ journalofethics.2017.19.3.pfor1-1703

Knapp, P., Raynor, D. K., Jebar, A. H., and Price, S. J. (2005). Interpretation of Medication Pictograms by Adults in the UK. Ann. Pharmacother. 39, 1227-1233. doi:10.1345/aph.1E483

Kobau, R., and Dilorio, C. (2003). Epilepsy Self-Management: A Comparison of Self-Efficacy and Outcome Expectancy for Medication Adherence and Lifestyle Behaviors Among People with Epilepsy. Epilepsy Behav. 4, 217-225. doi:10.1016/S1525-5050(03)00057-X

Kripalani, S., Robertson, R., Love-Ghaffari, M. H., Henderson, L. E., Praska, J., Strawder, A., et al. (2007). Development of an Illustrated Medication Schedule as a Low-Literacy Patient Education Tool. Patient Education Couns. 66, 368-377. doi:10.1016/j.pec.2007.01.020

Kripalani, S., Schmotzer, B., and Jacobson, T. A. (2012). Improving Medication Adherence through Graphically Enhanced Interventions in Coronary Heart 
Disease (IMAGE-CHD): a Randomized Controlled Trial. J. Gen. Intern. Med. 27, 1609-1617. doi:10.1007/s11606-012-2136-z

Lehane, E., and McCarthy, G. (2009). Medication Non-adherence-exploring the Conceptual Mire. Int. J. Nurs. Pract. 15, 25-31. doi:10.1111/j.1440172X.2008.01722.x

Ley, P. (1976). “"Towards Better Doctor-patient Communication," in In Communication between Doctors And Patients. Editor A. Bennett (Oxford University Press), 77-96.

Institute of Medicine US Committee on Health Literacy (2004). "The Extent and Associations of Limited Health Literacy," in Health Literacy: A Prescription to End Confusion. Editors L. Nielsen-Bohlman, A. M. Panzer, and D. A. Kindig (Washington: National Academies Press).

Machtinger, E. L., Wang, F., Chen, L.-L., Rodriguez, M., Wu, S., and Schillinger, D. (2007). A Visual Medication Schedule to Improve Anticoagulation Control: A Randomized, Controlled Trial. Jt. Comm. J. Qual. Patient Saf. 33, 625-635. doi:10.1016/S1553-7250(07)33072-9

Makoul, G., and Roloff, M. E. (1998). The Role of Efficacy and Outcome Expectations in the Decision to Withhold Relational Complaints. Commun. Res. 25, 5-29. doi:10.1177/009365098025001001

Mansoor, L., and Dowse, R. (2007). Written Medicines Information for South African HIV/AIDS Patients: Does it Enhance Understanding of Co-trimoxazole Therapy?. Health Education Res. 22, 37-48. doi:10.1093/her/cyl039

Mansoor, L. E., and Dowse, R. (2004). Design and Evaluation of a New Pharmaceutical Pictogram Sequence to Convey Medicine Usage. Ergon. SA $16,29-41$.

Mansoor, L. E., and Dowse, R. (2003). Effect of Pictograms on Readability of Patient Information Materials. Ann. Pharmacother. 37, 1003-1009. doi:10.1345/aph.1c449

Mansoor, L. E., and Dowse, R. (2006). Medicines Information and Adherence in HIV/AIDS Patients. J. Clin. Pharm. Ther. 31, 7-15. doi:10.1111/j.13652710.2006.00696.x

Mateti, U. V., Nagappa, A. N., Attur, R. P., Bairy, M., Nagaraju, S. P., Mallayasamy, S., et al. (2015). Preparation, Validation and User-Testing of Pictogram-Based Patient Information Leaflets for Hemodialysis Patients. Saudi Pharm. J. 23, 621-625. doi:10.1016/j.jsps.2015.01.022

Mayer, R. E. (2002). Multimedia Learning. Psychol. Learn. Motiv. 41, 85-139. doi:10.1016/S0079-7421(02)80005-6

Merks, P., Świeczkowski, D., Balcerzak, M., Drelich, E., Białoszewska, K., Cwalina, N., et al. (2018). The Evaluation of Pharmaceutical Pictograms Among Elderly Patients in Community Pharmacy Settings - a Multicenter Pilot Study. Ppa Vol. 12, 257-266. doi:10.2147/PPA.S150113

Michalopoulou, G., Falzarano, P., Arfken, C., and Rosenberg, D. (2010). Implementing Ask Me 3 to Improve African American Patient Satisfaction and Perceptions of Physician Cultural Competency. J. Cult. Divers. 17, 62-67.

Miller, T. A. (2016). Health Literacy and Adherence to Medical Treatment in Chronic and Acute Illness: A Meta-Analysis. Patient Education Couns. 99, 1079-1086. doi:10.1016/j.pec.2016.01.020

Mohan, A., Riley, B., Schmotzer, B., Boyington, D. R., and Kripalani, S. (2014). Improving Medication Understanding Among Latinos through Illustrated Medication Lists. Am. J. Manag. Care 20, e547-55.

Monroe, A. K., Pena, J. S., Moore, R. D., Riekert, K. A., Eakin, M. N., Kripalani, S., et al. (2018). Randomized Controlled Trial of a Pictorial Aid Intervention for Medication Adherence Among HIV-Positive Patients with Comorbid Diabetes or Hypertension. AIDS Care 30, 199-206. doi:10.1080/09540121.2017.1360993

Montagne, M. (2013). Pharmaceutical Pictograms: A Model for Development and Testing for Comprehension and Utility. Res. Soc. Administrative Pharm. 9, 609-620. doi:10.1016/j.sapharm.2013.04.003

Negarandeh, R., Mahmoodi, H., Noktehdan, H., Heshmat, R., and Shakibazadeh, E. (2013). Teach Back and Pictorial Image Educational Strategies on Knowledge about Diabetes and Medication/dietary Adherence Among Low Health Literate Patients with Type 2 Diabetes. Prim. Care Diabetes 7, 111-118. doi:10.1016/ j.pcd.2012.11.001

Ng, A. W. Y., Chan, A. H. S., and Ho, V. W. S. (2017). Comprehension by Older People of Medication Information with or without Supplementary Pharmaceutical Pictograms. Appl. Ergon. 58, 167-175. doi:10.1016/j.apergo.2016.06.005

Ngoh, L. N. (2009). Health Literacy: A Barrier to Pharmacist-Patient Communication and Medication Adherence. J. Am. Pharm. Assoc. 49, e132-e149. doi:10.1331/JAPhA.2009.07075
Ngoh, L. N., and Shepherd, M. D. (1997). Design, Development, and Evaluation of Visual Aids for Communicating Prescription Drug Instructions to Nonliterate Patients in Rural Cameroon. Patient Education Couns. 30, 257-270. doi:10.1016/S0738-3991(96)00976-7

Nguyen, T.-M. -U., Caze, A. L., and Cottrell, N. (2014). What Are Validated SelfReport Adherence Scales Really Measuring?: A Systematic Review. Br. J. Clin. Pharmacol. 77, 427-445. doi:10.1111/bcp.12194

Nieuwlaat, R., Wilczynski, N., Navarro, T., Hobson, N., Jeffery, R., Keepanasseril, A., et al. (2014). Interventions for Enhancing Medication Adherence. Cochrane Database Syst. Rev. 11, CD000011. doi:10.1002/ 14651858.CD000011.pub4

Omachi, T. A., Sarkar, U., Yelin, E. H., Blanc, P. D., and Katz, P. P. (2013). Lower Health Literacy Is Associated with Poorer Health Status and Outcomes in Chronic Obstructive Pulmonary Disease. J. Gen. Intern. Med. 28, 74-81. doi:10.1007/s11606-012-2177-3

Park, D. C., Willis, S. L., Morrow, D., Diehl, M., and Gaines, C. L. (1994). Cognitive Function and Medication Usage in Older Adults. J. Appl. Gerontol. 13, 39-57. doi:10.1177/073346489401300104

Park, M. (2011). Effects of Interactive Pictorial Education on Community Dwelling Older Adult's Self Efficacy and Knowledge for Safe Medication. J. Korean Acad. Nurs. 41, 795. doi:10.4040/jkan.2011.41.6.795

Peregrin, T. (2010). Picture This: Visual Cues Enhance Health Education Messages for People with Low Literacy Skills. J. Am. Diet. Assoc. 110, S28-S32. doi:10.1016/j.jada.2010.03.005

Peterson, P. N., Shetterly, S. M., Clarke, C. L., Bekelman, D. B., Chan, P. S., Allen, L. A., et al. (2011). Health Literacy and Outcomes Among Patients with Heart Failure. Jama 305, 1695-1701. doi:10.1001/jama.2011.512

Phimarn, W., Ritthiya, L., Rungsoongnoen, R., Pattaradulpithuk, W., and Saramunee, K. (2019). Development and Evaluation of a Pictogram for Thai Patients with Low Literate Skills. pharmaceutical-sciences 81, 89-98. doi:10.4172/pharmaceutical-sciences.1000483

Pignone, M. P., and DeWalt, D. A. (2006). Literacy and Health Outcomes. J. Gen. Intern. Med. 21, 896-897. doi:10.1111/j.1525-1497.2006.00545.x

Pouliot, A., Vaillancourt, R., Stacey, D., and Suter, P. (2018). Defining and Identifying Concepts of Medication Literacy: An International Perspective. Res. Soc. Administrative Pharm. 14, 797-804. doi:10.1016/ j.sapharm.2017.11.005

Re, L. Del., Villarreal, G., and Pouliot, A. (2016). Pictograms : Can They Help Patients Recall Medication Safety Instructions?. Visible Lang. 50, 127-151.

Richler, M., Vaillancourt, R., Celetti, S. J., Besançon, L., Arun, K., and Sebastien, F. (2012). The Use of Pictograms to Convey Health Information Regarding Side Effects And/or Indications of Medications. J. Commun. Healthc. 5, 220-226. doi:10.1179/1753807612y.0000000012

Roccella, E. J. (1997). The Sixth Report of the Joint National Committee on Prevention, Detection, Evaluation, and Treatment of High Blood Pressure. Arch. Intern. Med. 157, 2413-2446. doi:10.1001/archinte.157.21.2413

Sadoski, M., and Paivio, A. (2013). Imagery and Text: A Dual Coding Theory of Reading and Writing. 2nd ed. New York: Routledge. doi:10.4324/ 9780203801932

Schillinger, D., Grumbach, K., Piette, J., Wang, F., Osmond, D., Daher, C., et al. (2002). Association of Health Literacy with Diabetes Outcomes. Jama 288, 475-482. doi:10.1001/jama.288.4.475

Schubbe, D., Scalia, P., Yen, R. W., Saunders, C. H., Cohen, S., Elwyn, G., et al. (2020). Using Pictures to Convey Health Information: A Systematic Review and Meta-Analysis of the Effects on Patient and Consumer Health Behaviors and Outcomes. Patient Education Couns. 103, 1935-1960. doi:10.1016/ j.pec.2020.04.010

Sletvold, H., Sagmo, L. A. B., and Torheim, E. A. (2020). Impact of Pictograms on Medication Adherence: A Systematic Literature Review. Patient Education Couns. 103, 1095-1103. doi:10.1016/j.pec.2019.12.018

Smith, B., and Magnani, J. W. (2019). New Technologies, New Disparities: The Intersection of Electronic Health and Digital Health Literacy. Int. J. Cardiol. 292, 280-282. doi:10.1016/j.ijcard.2019.05.066

Sokol, M. C., McGuigan, K. A., Verbrugge, R. R., and Epstein, R. S. (2005). Impact of Medication Adherence on Hospitalization Risk and Healthcare Cost. Med. Care 43, 521-530. doi:10.1097/01.mlr.0000163641.86870.af

Sørensen, K., Pelikan, J. M., Röthlin, F., Ganahl, K., Slonska, Z., Doyle, G., et al. (2015). Health Literacy in Europe: Comparative Results of the European Health 
Literacy Survey (HLS-EU). Eur. J. Public Health 25, 1053-1058. doi:10.1093/ eurpub/ckv043

Sorfleet, C., Vaillancourt, R., Groves, S., and Dawson, J. (2009). Design, Development and Evaluation of Pictographic Instructions for Medications Used during Humanitarian Missions. Can. Pharm. J. 142, 82-88. doi:10.3821/1913-701X-142.2.82

Sullivan, S. D., Kreling, D. H., and Hazlet, T. (1990). Noncompliance with Medication Regimens and Subsequent Hospitalizations: a Literature Analysis and Cost of Hospitalization Estimate. J. Res. Pharm. Econ. 2, 19-33.

Tanner, S., Wells, M., Scarbecz, M., and McCann, B. W. (2014). Parents' Understanding of and Accuracy in Using Measuring Devices to Administer Liquid Oral Pain Medication. J. Am. Dental Assoc. 145, 141-149. doi:10.14219/ jada.2013.20

Tork, H. M. M. (2013). A Pictogram-Based Intervention to Reduce Parental Liquid Medication Errors: Health Literacy Approach. Ajns 2, 27-32. doi:10.11648/ j.ajns.20130203.12

UNESCO Institute for Statistics (2013). Adult and Youth Literacy: National, Regional and Global Trends, 1985-2015. Montreal. Availableat: http://uis. unesco.org/sites/default/files/documents/adult-and-youth-literacy-nationalregional-and-global-trends-1985-2015-en_0.pdf (Accessed July 6, 2020).

Vaillancourt, R., Truong, Y., Karmali, S., Kraft, A., Manji, S., Villarreal, G., et al. (2017). Instructions for Masking the Taste of Medication for Children. Can. Pharm. J. 150, 52-59. doi:10.1177/1715163516669383

Vermeire, E., Hearnshaw, H., Van Royen, P., and Denekens, J. (2001). Patient Adherence to Treatment: Three Decades of Research. A Comprehensive Review. J. Clin. Pharm. Ther. 26, 331-342. doi:10.1046/j.13652710.2001.00363.x

Vrijens, B., De Geest, S., Hughes, D. A., Przemyslaw, K., Demonceau, J., Ruppar, T., et al. (2012). A New Taxonomy for Describing and Defining Adherence to Medications. Br. J. Clin. Pharmacol. 73, 691-705. doi:10.1111/j.13652125.2012.04167.x

Wilby, K., Marra, C. A., da Silva, J. H., Grubisic, M., Harvard, S., and Lynd, L. D. (2011). Randomized Controlled Trial Evaluating Pictogram Augmentation of HIV Medication Information. Ann. Pharmacother. 45, 1378-1383. doi:10.1345/ aph.1q091

Wilhelmsen, N. C., and Eriksson, T. (2019). Medication Adherence Interventions and Outcomes: an Overview of Systematic Reviews. Eur. J. Hosp. Pharm. 26, 187-192. doi:10.1136/ejhpharm-2018-001725

Wolf, M. S., Feinglass, J., Thompson, J., and Baker, D. W. (2010). In Search of 'low Health Literacy': Threshold vs. Gradient Effect of Literacy on Health Status and Mortality. Soc. Sci. Med. 70, 1335-1341. doi:10.1016/ j.socscimed.2009.12.013

World Health Organization (2003). Adherence to Long-Term Therapies: Evidence for Action. Geneva. Availableat: https://apps.who.int/iris/bitstream/handle/ 10665/42682/9241545992.pdf; jsessionid=A2C64BFC70BE0933BFA894486BBAE6AF?sequence=1 (Accessed July 6,2020$)$.
World Health Organization (2005). Preventing Chronic Diseases: A Vital investmentWHO Global Report. Geneva. Availableat: https://www.who.int/ chp/chronic_disease_report/en/(Accessed July 6, 2020).

Wrench, W., van Dyk, L., Srinivas, S., and Dowse, R. (2019). Outcome of Illustrated Information Leaflet on Correct Usage of Asthma-Metered Dose Inhaler. Afr. J. Prim. Health Care Fam. Med. 11. doi:10.4102/phcfm.v11i1.2079

Yang, C.-M., and Hsu, T.-F. (2015). Applying Semiotic Theories to Graphic Design Education: An Empirical Study on Poster Design Teaching. Ies 8, 117-129. doi:10.5539/ies.v8n12p117

Yin, H. S., Dreyer, B. P., Van Schaick, L., Foltin, G. L., Dinglas, C., and Mendelsohn, A. L. (2008). Randomized Controlled Trial of a Pictogram-Based Intervention to Reduce Liquid Medication Dosing Errors and Improve Adherence Among Caregivers of Young Children. Arch. Pediatr. Adolesc. Med. 162, 814-822. doi:10.1001/archpedi.162.9.814

Yin, H. S., Gupta, R. S., Tomopoulos, S., Mendelsohn, A. L., Egan, M., Van Schaick, L., et al. (2016). A Low-Literacy Asthma Action Plan to Improve Provider Asthma Counseling: A Randomized Study. Pediatrics 137, e20150468. doi:10.1542/peds.2015-0468

Yin, H. S., Mendelsohn, A. L., Fierman, A., Van Schaick, L., Bazan, I. S., and Dreyer, B. P. (2011). Use of a Pictographic Diagram to Decrease Parent Dosing Errors with Infant Acetaminophen: A Health Literacy Perspective. Acad. Pediatr. 11, 50-57. doi:10.1016/j.acap.2010.12.007

Youmans, S. L., and Schillinger, D. (2003). Functional Health Literacy and Medication Use: The Pharmacist's Role. Ann. Pharmacother. 37, 1726-1729. doi:10.1345/aph.1D070

Zerafa, N., Zarb Adami, M., and Galea, J. (2011). Impact of Drugs Counselling by an Undergraduate Pharmacist on Cardiac Surgical Patient's Compliance to Medicines. Pharm. Pract. (Granada) 9, 156-161. doi:10.4321/S1886-36552011000300007

Conflict of Interest: The authors declare that the research was conducted in the absence of any commercial or financial relationships that could be construed as a potential conflict of interest.

Publisher's Note: All claims expressed in this article are solely those of the authors and do not necessarily represent those of their affiliated organizations, or those of the publisher, the editors and the reviewers. Any product that may be evaluated in this article, or claim that may be made by its manufacturer, is not guaranteed or endorsed by the publisher.

Copyright (ㄷ 2021 Merks, Cameron, Bilmin, Świeczkowski, ChmielewskaIgnatowicz, Harężlak, Białoszewska, Sola, Jaguszewski and Vaillancourt. This is an open-access article distributed under the terms of the Creative Commons Attribution License (CC BY). The use, distribution or reproduction in other forums is permitted, provided the original author(s) and the copyright owner(s) are credited and that the original publication in this journal is cited, in accordance with accepted academic practice. No use, distribution or reproduction is permitted which does not comply with these terms. 